\title{
Expression of meis and hoxa11 in dipnoan and teleost fins provides new insights into the evolution of vertebrate appendages
}

\author{
Fernanda Langellotto ${ }^{1}$, Maria Fiorentino ${ }^{2}$, Elena De Felice ${ }^{3}$, Luigi Caputi ${ }^{4}$, Valeria Nittoli ${ }^{5}$, Jean M. P. Joss ${ }^{6}$
} and Paolo Sordino ${ }^{5^{*}}$ (D)

\begin{abstract}
Background: The concerted activity of Meis and Hoxa11 transcription factors is essential for the subdivision of tetrapod limbs into proximo-distal (PD) domains; however, little is know about the evolution of this patterning mechanism. Here, we aim to study the expression of meis and hoxa11 orthologues in the median and paired rayed fins of zebrafish and in the lobed fins of the Australian lungfish.

Results: First, a late phase of expression of meis 1.1 and hoxa $11 b$ in zebrafish dorsal and anal fins relates with segmentation of endochondral elements in proximal and distal radials. Second, our zebrafish in situ hybridization results reveal spatial and temporal changes between pectoral and pelvic fins. Third, in situ analysis of meis 1, meis 3 and hoxa11 genes in Neoceratodus pectoral fins identifies decoupled domains of expression along the PD axis.

Conclusions: Our data raise the possibility that the origin of stylopod and zeugopod lies much deeper in gnathostome evolution and that variation in meis and hoxa11 expression has played a substantial role in the transformation of appendage anatomy. Moreover, these observations provide evidence that the Meis/Hoxa11 profile considered a hallmark of stylopod/zeugopod patterning is present in Neoceratodus.
\end{abstract}

Keywords: Fin-to-limb transition, Neoceratodus, Zebrafish, Hoxa11, Meis, Gene expression

\section{Background}

Early development of both fore and hindlimbs of tetrapods involves condensation of endochondral skeleton within a mesenchymal lateral plate projection. In a proximo-distal (PD) sequence, first to form is the single element upper arm (stylopod), which articulates with the pectoral girdle. The second is the dual-element forearm (zeugopod) followed by the final region of the hand (autopod). This last region is the most variable, contributing to give rise to such limb specializations as wings and flippers. In the study of the evolution of tetrapod

\footnotetext{
*Correspondence: paolo.sordino@szn.it

${ }^{5}$ Department of Biology and Evolution of Marine Organisms, Stazione

Zoologica Anton Dohrn, Villa Comunale, 80121 Naples, Italy

Full list of author information is available at the end of the article
}

appendages, the majority of interest has been directed at the origin and variation of genetic mechanisms required for the formation of the autopod (hand, foot) [1-12]. Currently, there has been less interest in the evolution of the molecular underpinnings that control the clear division between the stylopod (humerus, femur) and zeugopod (ulna/radius, tibia/fibula) [13]. In particular, little is known about exactly when the changes in genetic processes occurred that were responsible for the endoskeletal patterns changing from a lobed fin pattern to that of a tetrapod limb.

Skeletal and molecular patterns support the hypothesis that the first fins may have originated as median fins in stem group gnathostomes and that paired fins are unique to jawed vertebrates and their pre-jawed relatives [14, 15]. Primitively, endoskeletal patterns of median fins 
consisted of morphologically identical and unsegmented radials (early craniates, e.g., Myllokunmingia), which later became segmented in two (basal gnathostomes) or three sections (acanthopterygians) [16]. The first paired fins for which there is evidence of endoskeletal support appeared in a lineage of jawless fishes that led to the gnathostome stem group. The pectoral fins of ancestral fishes possessed an endoskeleton consisting of proximal radials (basals) articulating directly with their girdles [1719]. In living fishes, the number of radials is varied. The usual pattern in elasmobranchs is tribasal, made up of a propterygium, mesopterygium, and metapterygium [20], while the numbers of basals are much more diverse in teleost fishes and other members of the ray-finned clade (for an overview of actinopterygian paired fin anatomy, see [21]). Within actinopterygians, teleost fishes have lost the most posterior radial, the metapterygium [14]. Paleontological data suggest that the tetrapod limb originated from sarcopterygian fins by transformation of the endochondral architecture and loss of distal dermoskeleton [1-3]. Living sarcopterygians have retained exclusively the metapterygial elements and have lost the propterygium and mesopterygium [22]. In gnathostome pectoral fins, proximal radials articulate with distal row of smaller radials that originate by segmentation or de novo condensation [19]. The second set of paired appendages, the pelvic fins, appeared later in jawed vertebrates and are generally simpler in pattern, with an endoskeleton consisting of few rod-like basals [23-26]. A reductive trend of the number of radials resulting in the loss of basals is observed in pelvic fins of actinopterygians [22, 27].

Genetic approaches have led us to a point where the developmental mechanisms responsible for stylopod and zeugopod formation have been identified in limb. This process arises from the combined action of two genes encoding master regulators of transcription that have been identified as determinants of proximal and distal limb elements. The expression of Meis genes specifies stylopod cell identities, possibly in response to diffusible retinoic acid from flank cells, while Hoxa11 genes are critical for normal growth rates and differentiation in the zeugopod under the influence of FGF signaling from the apical ectodermal ridge (AER) [28-33]. Spatial and temporal signatures for Meis and Hoxa11 clearly distinguish between the stylopod and the zeugopod subdivisions and can be used as developmental landmarks for PD regionalization.

There is paucity of information about how the stylopod-zeugopod developmental program has changed during evolution and how this relates to morphological diversification. Chondrichthyans (sharks, rays, chimeras) retain most plesiomorphic features of primitive gnathostomes, including both midline and paired fins, and are a good model for phylogenetic sampling. Expression data are available pertaining paired fins of the smallspotted catshark, Scyliorhinus canicula [34-37] and the little skate, Leucoraja erinacea [38], making cartilaginous fishes a suitable outgroup to the actinopterygian fishes + sarcopterygians (lungfish, coelacanths and tetrapods) for testing hypotheses concerning the evolution of PD patterning mechanisms [39]. In chondrichthyans, pectoral fins develop by condensation of undifferentiated mesenchyme and by apoptosis [34]. During this process, meis and hoxa11 are expressed proximally and distally, respectively, suggesting that some aspects of the genetic program for limb PD patterning are shared among gnathostomes [35]. Yet, evidence of a physical boundary between expression patterns, as it is observed in limbs, is missing [34-38]. The ray-finned zebrafish and paddlefish are independently derived actinopterygian taxa with a duplicated genome (Whole Genome Duplication, WGD) [40]. In the pectoral fins of these fishes, hoxa11 and meis expression domains do not form a PD boundary and, in addition, gene expression wanes and ceases before radial formation [35-37, 41-45]. However, these data should be interpreted with caution when considering that zebrafish is a highly derived teleost and paddlefish is a living representative of chondrosteans and, as such, sister group to the neopterygians. The HoxA cluster generated by WGD appears to be inactive, with only a single paralog of each $5^{\prime}$ gene expressed in the developing fin [36, 46, 47], making necessary to be aware of which possible hoxa11 paralogue ( $\mathrm{a}$ or $\mathrm{b}$ ) is examined. To our knowledge, there is no reported evidence of hoxa11 and meis gene expression patterns during the development of paired fins of sarcopterygian fishes and in median or pelvic rayed fins of actinopterygian fishes.

While sarcopterygians primitively had polybasal paired fins [48], crown taxa appear to possess a one to two, proximo-distal ratio of appendicular cartilages or bones that are morphologically homologous to the stylopod and zeugopod of tetrapod limbs [49-53]. To date, molecular markers have not been applied to back up this morphological identification. This is primarily because only a handful of lungfish and coelacanth species have survived as sarcopterygian fish alive today. Since all tetrapods are also sarcopterygians, and Dipnoi as a whole are generally supported as the sister group of Tetrapoda, there is really only one fish whose paired fins are worth, by far, testing molecular markers for stylopod and zeugopod development. Coelacanths (only 2 living species) are deep-sea marine viviparous species both of which are listed as endangered and are less closely related to early tetrapods $[54,55]$. Living lungfish occur in 2 families, the Lepidosirenidae (5 species) and the Ceratodidae (single species, Neoceratodus forsteri). It is only this latter that occurs close enough to habitation to make it feasible for 
molecular developmental study to compare with tetrapod and ray-finned fish paired fin early development to be carried out [56-59]. The lobed fins of Neoceratodus have an elongated axis generally considered as metapterygial, with pre- and post-axial radials [14]. A closer analysis of the morphological and genetic pathways in the development of paired fins in Neoceratodus may have implications for the developmental changes involved in the evolution of a paired lobed fin into a tetrapod limb.

Experiments on fish at other phylogenetic positions are needed to draw homologies based on comparative gene expression. Here, we aim to track the expression of Meis and Hoxa11 genes in median and pelvic fins of zebrafish, and in paired fins of the Australian lungfish. A comparative analysis may give clue to the degree of variation in the activity of these developmental landmarks. How flexible PD patterning mechanisms are in jawed vertebrate appendages is still a poorly explored issue, nor is the sequence and timing of this process clear.

\section{Methods \\ Embryos}

Zebrafish embryos were obtained from natural spawning of wild-type ( $\left.A B^{*}\right)$ fish. Lungfish were obtained as fertilized eggs from dedicated spawning ponds established at Macquarie University and reared to appropriate stages prior to fixation in buffered $4 \%$ paraformaldehyde. Lungfish were fixed for 24-48 h (depending on size), rinsed in buffer, transferred to $100 \%$ methanol, and stored at $-20^{\circ} \mathrm{C}$.

\section{Cloning}

Neoceratodus forsteri RNA was extracted from stage 40-42 embryos (RNeasy, Qiagen), followed by cDNA synthesis (Smart Race, Clontech). To amplify meis cDNAs, full-length nucleotide and amino acid sequences of vertebrate homologs were aligned to design degenerate oligonucleotides in conserved regions: Meis-fw GCT GGCHCTSATYTTYGARAARGYGA and Meis-rev CGTCKTCKKGCRTTRATRAACCARTT. PCR fragments of lungfish meis1 and meis3 genes were cloned, sequenced and analyzed. Neoceratodus hoxa11 fulllength cDNA was kindly provided by $M$. Sutija who amplified it with Hoxa11-fw2 TCCDGATTTCTCCAGC CTSCC and Hoxa11-rev1 CAGATTTTAACTTGACGG TCGGT based on previous sequence [60].

\section{Phylogeny}

Amino acid sequences of lungfish Hox and Meis and of their vertebrate orthologues were gathered from public databases and aligned using Muscle v3.8.31 [61]. The alignments were visually checked using Bioedit v7.0.5.3 [62]. Hoxa11 affiliation was confirmed with the program
HoxPred (URL: http://cege.vub.ac.be/hoxpred) [63]. The best fitting amino acid substitution models for the Hox and Meis alignments were selected using ProtTest 3 [64], using the "fast" option and under a full coverage of the amino acidic substitution matrices and of the specific corrections therein proposed. The Akaike information criterion (AIC), the Akaike second-order information criterion (AICc) and the Bayesian information criterion (BIC) selected the JTT $+\mathrm{I}+\mathrm{G}$ as the best fitting model for the Hox $(\gamma=2.078)$ and Meis $(\gamma=0.572)$ alignments. The ProtTest 3 results were used to constrain "Neighbor Joining" (NJ) and "Maximum Likelihood" phylogenies. The NJ constrained phylogeny was inferred using MEGA5 [65] under the JTT model of amino acidic evolution and performing 10,000 bootstrap replicates. The ML phylogeny was inferred using the software PhyML 3.0 [66], performing 1000 bootstrap replicates. Finally, Maximum Parsimony (MP) phylogeny was inferred after performing 500 bootstrap replicates using the close neighbor interchange (CNI) on random tree search method and 1000 initial trees on MEGA5. The topologies inferred with the three methods are substantially similar for both Meis and Hox protein phylogenetic analyses. The nucleotide sequences of lungfish meis1, meis3 and hoxa11 genes are deposited in GenBank database under the accession numbers: [GenBank sequence submission ongoing].

\section{Labeling}

For zebrafish ( $n=10$ embryos per experiment; data gathered from 5 embryos), standard methods for wholemount in situ hybridization (WISH) with digoxigeninlabeled riboprobe and for single color labeling were used. For lungfish $(n=4-5 ; 2-3)$, single WISH with digoxigenin-labeled riboprobes were carried out according to standard methods modified for better riboprobe penetration by elongating the proteinase $\mathrm{K}$ treatment step [56]. No staining was detected when using sense probes. The precise expression boundary between Neoceratodus meis and hoxa11 genes could not be adequately resolved since the hoxa11 riboprobe did not work in double WISH experiments. To correlate gene expression patterns with cartilage condensations, Alcian Blue staining was performed before WISH. Labeled fins were removed with Dumont forceps and mounted in glycerol for imaging with the AxioImager M1 (Zeiss) microscope or processed for cross sections in Epoxy resin. Differential Interference Contrast microscopy images were acquired with a Zeiss Axio Imager M1 microscope equipped with an Axiocam digital camera. Figure plates were made with Adobe Photoshop CS4. Brightness/contrast and color balance adjustments where applied, were applied to the entirety of the image and not to parts thereof. 


\section{Results}

\section{Meis 1.1 and Hoxa $11 \mathrm{~b}$ expression during cartilage} segmentation in dorsal and anal fins of zebrafish

We investigated meis and hoxa11 gene expression with respect to chondrogenesis in dorsal and anal fins of zebrafish. By whole-mount in situ hybridization (WISH) experiments, meis3.1 and hoxa11a were not expressed during the development of these median fins. In contrast, meis1.1 and hoxa11b genes showed three distinct phases of expression. When the dorsal fin bud is hardly visible, flattened stacks of chondrocytes form undivided cartilage rods (notochord length, $\mathrm{NL}=3.6-4.4 \mathrm{~mm}$; somites 15 th to 17 th). At this stage, meis 1.1 was first expressed in a narrow territory immediately under the apical ectodermal ridge (AER) (Fig. 1a). On the other hand, cells positive for hoxa11b expression were seen at the base

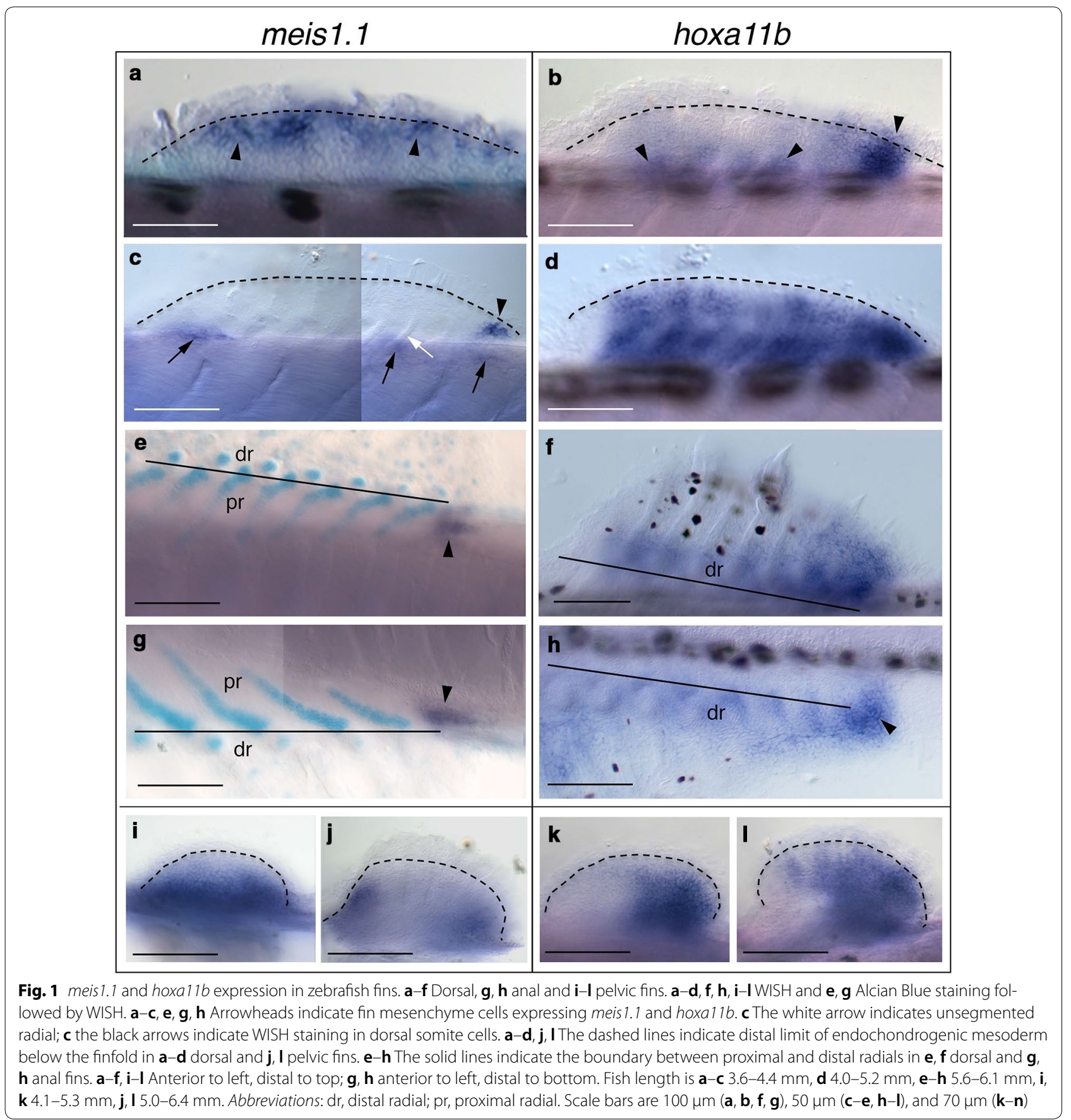


of the fin bud and also in the posterior fin mesenchyme (Fig. 1b). Before radial segmentation $(\mathrm{NL}=4.0-5.2 \mathrm{~mm})$, meis1.1 expression had become posterior; meis1.1 transcript was observed also in dorsal somite cells (Fig. 1c). With the onset of radial segmentation $(\mathrm{NL}=5.0$ $5.4 \mathrm{~mm})$, hoxa11b expression extended across the fin except the anterior margin, in a way reminiscent of latephase expression of hoxa11 orthologous in paired rayed fins and limbs [38-40, 43] (Fig. 1d). At late stage of radial segmentation $(\mathrm{NL}=5.6-6.1 \mathrm{~mm})$ during the posterior expansion of the radials array, meis1.1 mRNA signal was seen at the site of chondrogenesis of the last proximal radial (Fig. 1e, g), and hoxa11a expression in the mesenchyme between distal radials (Fig. 1f, h). Thus, latephase expression of meis1.1 and hoxa11b correlates with endoskeletal regionalization along the PD axis.

\section{Expression of Meis1.1 and Hoxa11b in pelvic fins of zebrafish}

Studies of meis1 and hoxa11 gene expression patterns in pectoral fins of shark, paddlefish and zebrafish revealed some substantial differences [36, 37, 41-45]. Here, we are interested to investigate whether a similar phylogenetic variation exists also within lineages, i.e., between anterior and posterior paired appendages of teleosts. The first phase of meis 1.1 and hoxa11b expression in zebrafish pelvic fin buds was very similar to pectorals, with proximal and posterior mRNA restriction, respectively ( $\mathrm{NL}=4.1-5.3 \mathrm{~mm}$ ) (Fig. 1i, k) [41-43]. Later, both transcription factors were transcribed during chondrification in pelvics $(\mathrm{NL}=5.0-6.4 \mathrm{~mm})$. In particular, transcriptional activity of meis1.1 was restricted proximally to anterior and posterior margins (Fig. 1j), and hoxa11b expression was anteriorly expanded, resembling the second phase of hoxa11 regulation in pectoral fins and limbs $[45,67]$ (Fig. 11). Late-phase expression of meis1.1 in pelvic fins is particularly interesting because in pectoral fins this signal is rapidly polarized to the proximal terminus during fin skeleton reorganization (Additional file 1).

\section{Evidence of a molecular stylopod/zeugopod boundary in paired fins of Neoceratodus}

To discover whether the development of paired lobed fins displays mRNA domains that are consistent with the stylopod/zeugopod homology supported by morphological studies, we examined meis1, meis3 and hoxa11 transcriptional profiles in lungfish, under the assumption that genes involved in PD patterning should behave similarly in paired lobed fins and limbs. PCR fragments of $N$. forsteri genes were obtained using degenerate primers designed against conserved regions of such genes in other species on total cDNA from stage $40-48$ whole embryos. The affiliation of Neoceratodus meis1 (718 bp), meis3 (732 bp) and hoxa11 (774 bp) cDNA sequences was suggested in a Blastx search against NCBI nonredundant protein sequences $(\mathrm{nr})$ and was clearly indicated by sequence alignments (Additional file 2: Fig. 2a, b). The position of $N$. forsteri predicted proteins within the topologies is consistent with their basal location to tetrapods [54, 55] (Additional file 2: Fig. 2c, d).

WISH was performed by use of digoxigenin-labeled antisense riboprobes synthetized from the entire cDNA fragments. The hoxa11 probe spans the entire coding sequence, while meis 1 and meis 3 probes target the entire MEIS domain and most of the homeodomain (Additional file 3). In the nascent paired fins of Neoceratodus, meis1 expression is restricted in mesenchymal cells under the AER, while meis 3 mRNA signal is expanded in the entire bud mesenchyme (st. 42, pectorals; st. 48, pelvics) (Fig. 2a-d) (Additional file 4: Fig. 4a). During chondrogenesis (st. 46-48), meis1 and meis3 were diffusely expressed in the proximal third of the pectoral fin, and in a segmentally reiterated pattern extending distally during development (Fig. 2e, f, i, j) (Additional file 4: Fig. 4b, c). Later in development, meis1 and meis3 expression was present in the intersegmental mesenchyme (st. 50) (Fig. 2g, k). Combining WISH and Alcian Blue (st. 46-48), the proximal domain of meis 1 and meis 3 expression was recognized in the region where the humerus cartilage differentiates (Fig. 2h, l).

In the paired fin buds of the Australian lungfish, the expression of hoxa11 was restricted to a posterior area of mesenchymal cells named the polarizing region, as seen in other tetrapod appendages (st. 43) (Fig. 3a) [67]. During fin outgrowth, hoxa11 transcription was turned on in more anterior cells in the distal aspect of the fin; of note, a PD discontinuity in the unique and continuous domain became visible between st. 43 and 44 (st. 43-44) (Fig. 3bd). Poor ability of hoxa11 mRNA riboprobe to generate a detectable signal in combination with Alcian Blue did not allow relating gene expression to anatomy. However, comparable st. 46 embryos suggest that hoxa11 expression is excluded proximally from the region where the humerus cartilage differentiates (Fig. 3e, f). Neoceratodus hoxa11 was transcribed in several other developing tissues, including neural tube, somites and digestive system (Additional file 5).

\section{Discussion}

Here, findings raise the possibility that some aspects of the role of meis and hoxa11 in PD regionalization also operated in the development of median fins of early vertebrates. It was reported that median fins share several anatomical and molecular traits with limb development, 


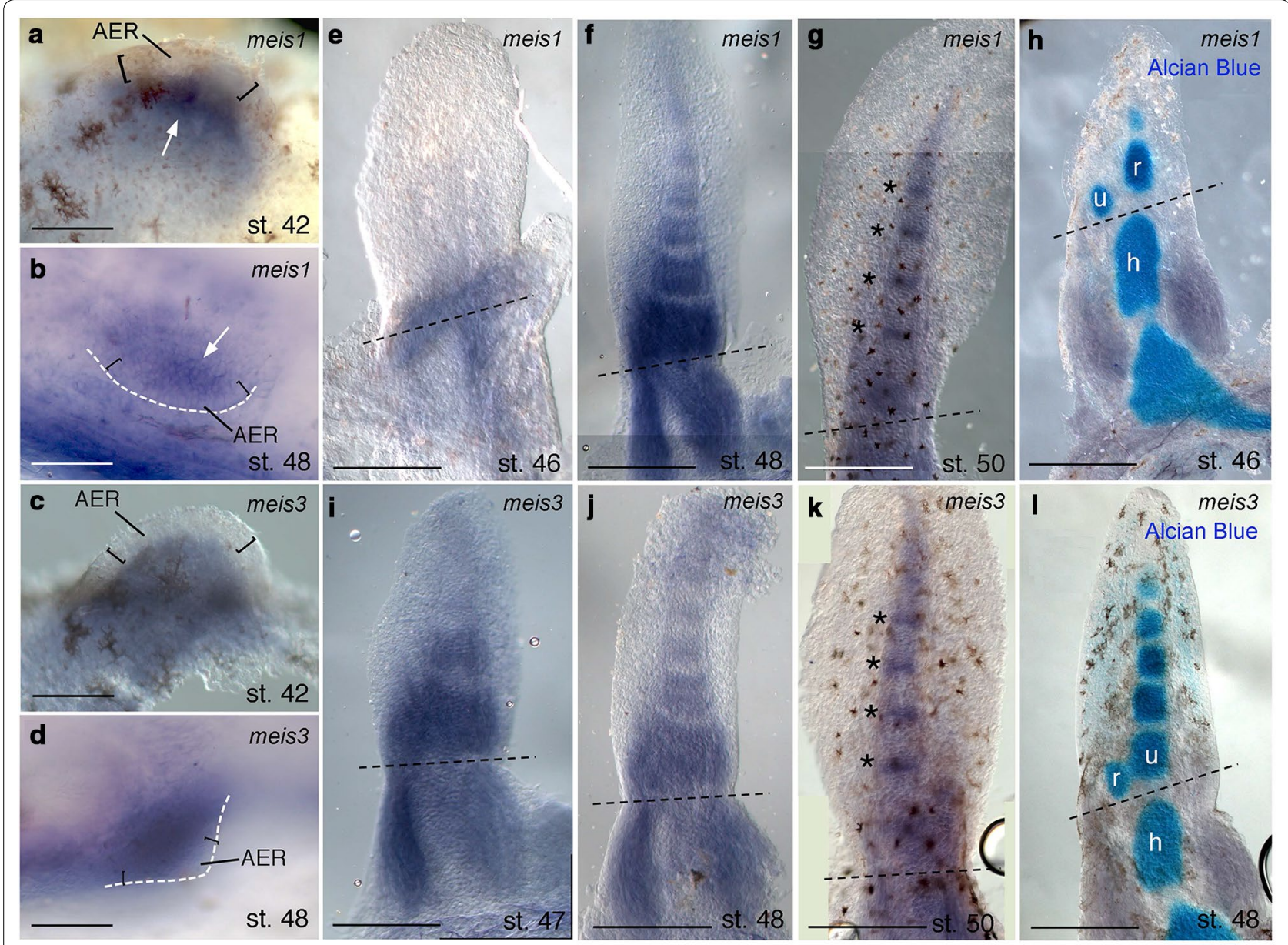

Fig. 2 meis 1 and meis 3 expression in Neoceratodus lobed fins. Whole-mount in situ hybridization in $\mathbf{a}, \mathbf{c}, \mathbf{e}-\mathbf{I}$ pectoral and $\mathbf{b}$, $\mathbf{d}$ pelvic lobed fins. a, b White arrowheads indicate meis 1 transcript under the AER in a pectoral and $\mathbf{b}$ pelvic fin buds. $\mathbf{c}-\mathbf{g}, \mathbf{i}-\mathbf{k}$ meis 3 expression in the whole bud of $\mathbf{c}$ pectoral and $\mathbf{d}$ pelvic fins. $\mathbf{b}$, $\mathbf{d}$ The white dashed lines highlight the margin of paired pelvic fin buds. a-d Square brackets indicate the AER. The black dashed lines indicate the stylopod-zeugopod boundary at chondrogenesis stages. $\mathbf{e}-\mathbf{g}, \mathbf{i}-\mathbf{k}$ From st. 46 to st. 50, e, i meis 1 and meis 3 transcripts are first localized in the proximal cells of the pectoral lobed fin, $\mathbf{f}, \mathbf{j}$ after they extend gradually in a PD striped pattern around cartilage condensations, $\mathbf{g}$, $\mathbf{k}$ and then they show intersegmental expression (asterisks). $\mathbf{h}$, I Double Alcian Blue/WISH labelings show proximal expression across the humerus region and the first transversal stripe near radius/ulna cartilages. Abbreviations: AER, apical ectodermal ridge; $c$, cartilage; $h$, humerus; $m$, mesenchyme; r, radius; $\mathbf{u}, \mathbf{u l n a}$. Anterior to left; distal to top. Scale bars are $100 \mu \mathrm{m}(\mathbf{a}-\mathbf{d}), 80 \mu \mathrm{m}(\mathbf{e}, \mathbf{f}, \mathbf{i})$ and $50 \mu \mathrm{m}(\mathbf{g}, \mathbf{h}, \mathbf{j}-\mathbf{I})$

indicating that some features of the primitive genetic mechanism for median fin development have been recruited in a new position to provide patterning information for paired pectoral fins [10, 15, 34]. This hypothesis is further supported by the correspondence in timing and pattern of expression of segmentation genes in median and paired fins $[68,69]$. Here, we found that late-phase expression of meis1.1 and hoxa11b is associated with the formation of proximal and distal radials, respectively, in the dorsal and anal fins of zebrafish, a condition that is neither found in paired fins of derived nor basal lineages of actinopterygian fishes [37, 41-45]. Late-phase restriction of meis1.1 and hoxa11b expression patterns in dorsal and anal fins of zebrafish suggests that the evolutionary roots of limb subdivisions rely on a common theme in the development of vertebrate appendages. These domains of meis 1.1 and hoxa11b expression are not considered stylopod- and zeugopod-like, as they inform positional cues that have probably been important for generating morphological diversity in all animal appendages [70-72]. To confirm or falsify this hypothesis, expression of meis and hoxa11 orthologues as well as of other regionalization and segmentation genes must be investigated in chondrichthyan (e.g., small-spotted catshark) and in non-teleostean actinopterygian clades (e.g., spotted gar, paddlefish and bichir) in detail. After the evaluation of catshark hoxa11 and meis 1 patterns by Sakamoto and coauthors [35], and of paddlefish hoxa11 

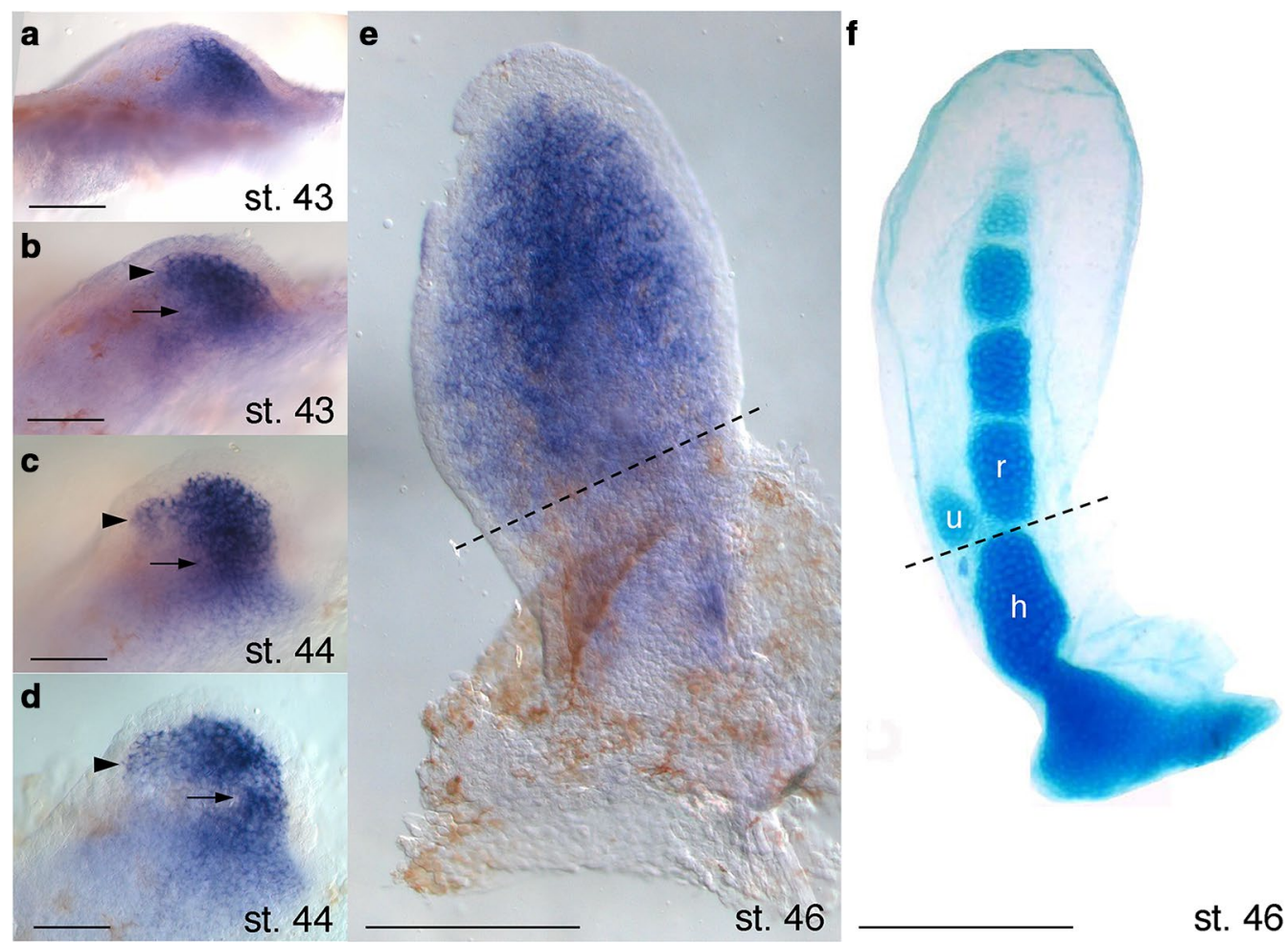

Fig. 3 hoxa 11 expression in Neoceratodus lobed fins. WISH in pectoral lobed fins from early budding to early chondrogenesis. a Distribution of hoxa11 transcript in the posterior bud. b-d The arrowheads indicate expression in anterior cells at the distal margin of the lungfish pectoral fin. $\mathbf{b}-\mathbf{d}$ The arrows indicate a PD discontinuity of low, if any, expression in the early phase of hoxa 11 activity. e, $\mathbf{f}$ Comparison of single WISH and Alcian Blue staining indicates that transcription is depleted in those cells that will ultimately build the humerus (below dashed line). Abbreviations: $h$, humerus; $r$, radius; $u$, ulna. Distal to top, anterior to left. Scale bars are $100 \mu \mathrm{m}(\mathbf{a}-\mathbf{d})$ and $50 \mu \mathrm{m}(\mathbf{e}, \mathbf{f})$

and meis 2 patterns by Tulenko and coauthors [37], it became clear that a true PD boundary is not present in the paired fins of chondrichthyan and actinopterygian fishes. However, the presence of a late-phase PD pattern of hoxa11b and meis1.1 in zebrafish dorsal and anal fins suggests that some aspects of the genetic program for limb PD patterning are shared among gnathostomes (Fig. 4),

Ray-finned fishes show a significant range of morphological and functional disparities in their pectoral and pelvic fins, and the reductive evolution of this dimorphism in tetrapod appendages is considered one of the most important differences between the two groups [19, $25,26,73]$. Regulation of meis 1.1 and hoxa11b expression is different in zebrafish pectoral and pelvic fins [41, 42]. The domain of meis1.1 expression in pelvic fins extended proximo-distally to the anterior and posterior mesenchyme, in support of the hypothesis of a proximalized skeleton phenotype (Fig. 1j). Differential expression of transcription factors between paired fin types of zebrafish may also reflect a developmental change in signaling pathways [74-77]. We hypothesize that spatial and temporal changes in the expression of these genes correlate with the complexity of fin skeletal patterns and with flexible morphology and function that have probably facilitated the adaptations of paired fins to various environments.

The stylopod/zeugopod (SZ) boundary of meis and hoxa11 in the sarcopterygian lungfish pectoral fins provides a molecular basis for the phylogenetic homologies between tetrapod forelimb and lungfish pectoral fins $[49,50]$. In our study, meis 1 and hoxa11 gene expression domains in Neoceratodus paired pectoral fins closely resemble those of tetrapod limbs, in that both structures have a $S / Z$ boundary during their growth and patterning. While all four clusters of tetrapod Hox genes are expressed, $5^{\prime}$ genes of the A cluster are most significant in specifying proximo-distal patterning and the D cluster in antero-posterior orientation $[2,78,79]$. Hox gene expression during the development of tetrapod limbs occurs in two distinct phases associated with different regions of the limb. During outgrowth of paired lobed fins, a unique extended domain of hoxa11 expression becomes disconnected along the proximo-distal axis by the creation of 


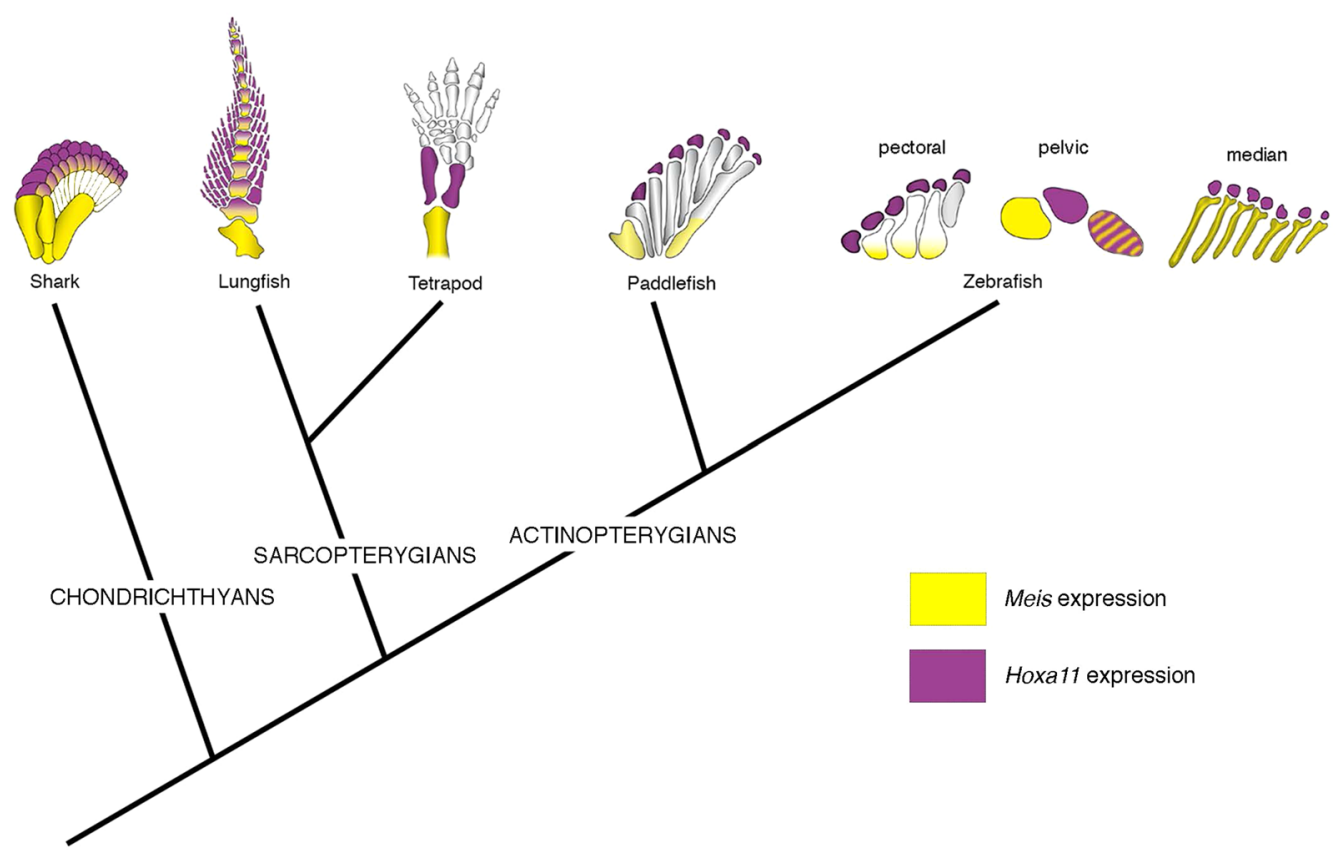

Fig. 4 Late-phase Meis and Hoxa11 expression in vertebrate appendages. The tree shows phylogenetic relationships of chondrichthyans, sarcopterygians and actinopterygians. Meis (yellow) and Hoxa11 (purple) expression domains at late stage of fin/limb development superimposed on the appendicular skeleton for each taxon

a zone with cells producing low mRNA. The question of whether the region with low hoxa11 expression observed in lungfish fins possesses a "mesopodial identity", as a zone of transition between two distinct phases of hoxa11 expression, or it is merely labeling the separation between elongated bones (the humerus and the ulna/radius), "cannot be solved by the mere contemplation of expression patterns" [78] and thus requires more evidence [44, 78, 80]. Here, the fundamental difference in Hox gene expression between a dipnoan fin and a tetrapod limb is the overlap between the expression domains of hoxa11 and hoxd13 throughout the region representing lobed fin radials [56, 81]. Co-expression of these two genes also occurs during rayed fin development, but it is very early in comparison with lungfish fins where it is found after the homologues of the stylopod and zeugopod have begun to condense [40, 43, 44]. Thus, in terms of Hox gene expression, the paired fins of $N$. forsteri may be viewed as lacking an autopod (hoxd13 expression is not exclusive to a distal region beyond hoxa11 expression).

\section{Conclusions}

Our findings for Neoceratodus specifically highlight the homology of stylopod and zeugopod elements described previously from fossil and morphological evidence. This leaves only the autopod as a possible tetrapod invention.
The reiterated Meis expression is a clear separation from the position in tetrapod limbs and must represent a distal developmental pattern of the paired lobed fin of the Australian lungfish. If we consider the segmental pattern of Meis gene expression in lobed fins and its absence in tetrapod limbs to be a clear fin $v s$ limb patterning, it calls into question the concept of a metapterygial axis equating to various autopodal parts [82]. The evidence in paddlefish pectoral fins of proximal meis 2 expression makes us favor the hypothesis of distal meis 1 and meis 3 expression pattern being simply an independently derived dipnoan specialization. Certain apomorphies of paired lobed fins, such as distal Meis expression, are perhaps to be expected given the current phylogenetic position of dipnoans relative to tetrapods, as the extant sister group to the Tetrapoda, but more phylogenetically distant relative to a number of fossil sarcopterygians [83, 84]. In effect, proximo-distal sequence of Meis expression along the metapterygial axis of lobed fins seems to be supportive of the role of segmentation for limb development [85]. Morphologically, lungfish fins have both stylopod and zeugopod equivalents. One century after its proposal, we provide the first molecular validation of W. K. Gregory's breakthrough view that the upper and forearm of the tetrapod limb originated from the skeletal elements of crown-sarcopterygian fishes $[49,50]$. 


\section{Additional files}

Additional file 1: Fig. 1 meis 1.1 expression and chondrogenesis in zebrafish pectoral fins. mRNA labeling shows proximal restriction during cartilage remodeling.

Additional file 2: Fig. 2 Alignment and phylogenetic analysis of Neoceratodus proteins. Partial protein-translated alignment and molecular phylogeny in ortholog identification of Neoceratodus meis1, meis3 and hoxa11.

Additional file 3: Fig. 3 Position of lungfish riboprobes. WISH riboprobes spanning mature mRNAs.

Additional file 4: Fig. 4 meis3 expression in developing pectoral fins of Neoceratodus. Transversal sections of in situ results at st. 42 and 47.

Additional file 5: Fig. 5 hoxa11 expression in lungfish. In situ results in nervous system, tail and digestive tract.

\section{Authors' contributions}

JMPJ and PS conceived of the project, wrote the manuscript, prepared all figures and provided financial support through grant application, JMPJ collected lungfish embryos, MF cloned lungfish Meis genes, FL performed lungfish experiments, EDF performed zebrafish experiments, VN participated in the design of the study and helped in the draft of the manuscript, and LC carried out the phylogenetic analyses. All authors read and approved the final manuscript.

\section{Author details \\ 1 Dragonfly Therapeutics, Inc., 35 Gatehouse Drive, Waltham, MA 02451, USA. ${ }^{2}$ Department of Pediatrics, Massachusetts General Hospital, Harvard Medi- cal School, East Building 114, 16th Street, Charlestown, MA, USA. ${ }^{3}$ School of Biosciences and Veterinary Medicine, University of Camerino, Via R. Fidanza 15, 62024 Matelica, Italy. ${ }^{4}$ Department of Integrated Marine Ecology, Stazione Zoologica Anton Dohrn, Villa Comunale, 80121 Naples, Italy. ${ }^{5}$ Department of Biology and Evolution of Marine Organisms, Stazione Zoologica Anton Dohrn, Villa Comunale, 80121 Naples, Italy. ${ }^{6}$ Biological Sciences, Macquarie University, Balaclava Road, North Ryde, Sydney, NSW 2109, Australia.}

\section{Acknowledgements}

We thank Gianluca De Rienzo, Rolf Ericsson, Charles Sagerstrom and Margareta Sutija for reagents; Elio Biffali for technical support at the Service of Molecular Biology of the Stazione Zoologica Anton Dohrn; Alison Cole, Salvatore D'Aniello, Alessandro Minelli, Remo Sanges, Günter Wagner and Jozsef Zakany for comments on this manuscript.

\section{Competing interests}

The authors declare that they have no no competing interests.

\section{Availability of data and supporting materials}

All data generated or analyzed during this study are included in this published article (and its supplementary information files).

\section{Consent for publication}

All authors gave final approval for publication.

\section{Ethics approval and consent to participate}

All lungfish care and experimental procedures were approved by the Animal Research Authority (ARA) at Macquarie University (ARA 2009/039). Experiments involving zebrafish were authorized by the Ethics Committee of the University of Naples Federico II (May 10th, 2013) according to the D.Lgs.n. 116/1992.

\section{Funding}

This work was supported by a MIUR project (Grant No. C08c-24), a MIUR Progetto Premiale, a MIUR PONa3 project (Grant No. 239), a FIRB project (Grant No. RBFR12QW4I), and two doctoral fellowship from Stazione Zoologica Anton Dohrn, Università di Napoli "Federico II", and University of Messina, Italy. Funding bodies had no role in the design of the study and collection, analysis, and interpretation of data and in writing the manuscript.

\section{Publisher's Note}

Springer Nature remains neutral with regard to jurisdictional claims in published maps and institutional affiliations.

Received: 14 February 2018 Accepted: 20 April 2018

Published online: 27 April 2018

\section{References}

1. Shubin N. The evolution of paired fins and the origin of tetrapod limbsPhylogenetic and transformational approaches. Evol Biol. 1995;28:39-86.

2. Shubin N, Tabin C, Carroll S. Fossils, genes and the evolution of animal limbs. Nature. 1997;388:639-48.

3. Coates MI, Jeffery JE, Rut M. Fins to limbs: what the fossils say. Evol Dev. 2002:4:390-401.

4. Wagner GP, Chiu CH. The tetrapod limb: a hypothesis on its origin. J Exp Zool B Mol Dev Evol. 2001;291:226-40.

5. Coates MI, Ruta M. Skeletal changes in the transition from fins to limbs. In: Hall BK, editor. Fins to limbs: evolution, development, and transformation. Chicago: University of Chicago; 2007. p. 15-38.

6. Clack JA. The fin to limb transition: new data, interpretations, and hypotheses from paleontology and developmental biology. Annu Rev Earth Planet Sci. 2009;37:163-79.

7. Schneider I, Aneas I, Gehrke AR, Dahn RD, Nobrega MA, Shubin NH. Appendage expression driven by the Hoxd Global Control Region is an ancient gnathostome feature. Proc Natl Acad Sci USA. 2011;108:12782-6.

8. Schneider I, Shubin NH. The origin of the tetrapod limb: from expeditions to enhancers. Trends Genet. 2013;29:419-26.

9. Freitas R, Gómez-Marín C, Wilson JM, Casares F, Gómez-Skarmeta JL. Hoxd13 contribution to the evolution of vertebrate appendages. Dev Cell. 2012;23:1219-29.

10. Freitas R, Gomez-Skarmeta JL, Rodrigues PN. New frontiers in the evolution of fin development. J Exp Zool B Mol Dev Evol. 2014;322:540-52.

11. Woltering JM, Noordermeer D, Leleu M, Duboule D. Conservation and divergence of regulatory strategies at Hox Loci and the origin of tetrapod digits. PLoS Biol. 2014;12:e1001773.

12. Gehrke AR, Schneider I, de la Calle-Mustienes E, Tena JJ, Gomez-Marin C, Chandran $\mathrm{M}$, et al. Deep conservation of wrist and digit enhancers in fish. Proc Natl Acad Sci USA. 2015;112:803-8.

13. Tarchini B, Duboule D. Control of Hoxd genes' collinearity during early limb development. Dev Cell. 2006;10:93-103.

14. Coates I. The origin of vertebrate limbs. Development. 1994;Suppl:169-80.

15. Freitas R, Zhang G, Cohn MJ. Evidence that mechanisms of fin development evolved in the midline of early vertebrates. Nature. 2006;442:1033-7.

16. Mabee PM, Crotwell PL, Bird NC, Burke AC. Evolution of median fin modules in the axial skeleton of fishes. J Exp Zool B Mol Dev Evol. 2002;294:77-90.

17. Janvier P. Early vertebrates. Oxford: Clarendon; 1996.

18. Janvier $P$, Arsenault M, Desbiens S. Calcified cartilage in the paired fins of the osteostracan Escuminaspis laticeps (Traquair 1880), from the Late Devonian of Miguasha (Quebec, Canada), with a consideration of the early evolution of the pectoral fin endoskeleton in vertebrates. J Vert Paleontol. 2004:24:773-9.

19. Coates MI. The evolution of paired fins. Theory Biosci. 2003;122:266-87.

20. Mabee PM. Developmental data and phylogenetic systematics: evolution of the vertebrate limb. Am Zool. 2000;40:789-800.

21. Jessen H. Schultergurtel und Pectoralflosse bei Actinopteryiern. Foss Strata. 1972;1:1-101.

22. Coates MI, Cohn MJ. Fins, limbs, and tails: outgrowths and axial patterning in vertebrate evolution. BioEssays. 1998;20:371-81.

23. Stiassny MLJ, Moore JA. A review of the pelvic girdle of acanthomorph fishes, with comments on hypotheses of acanthomorph intrarelationships. Zool J Linn Soc. 1992;104:209-42.

24. Grandel H, Schulte-Merker S. The development of the paired fins in the zebrafish (Danio rerio). Mech Dev. 1998;79:99-120.

25. Yamanoue Y, Setiamarga DHE, Matsuura K. Pelvic fins in teleosts: structure, function and evolution. J Fish Biol. 2010;77:1173-208. 
26. Don EK, Currie PD, Cole NJ. The evolutionary history of the development of the pelvic fin/hindlimb. J Anat. 2013;222:114-33.

27. Cubbage CC, Mabee PM. Development of the cranium and paired fins in the zebrafish Danio rerio (Ostariophysi, Cyprinidae). J Morphol. 1996:229:121-60.

28. Davis AP, Witte DP, Hsieh-Li HM, Potter SS, Capecchi MR. Absence of radius and ulna in mice lacking Hoxa-11 and Hoxd-11. Nature. 1995;375:791-5.

29. Capdevila J, Tsukui T, Rodríquez Esteban C, Zappavigna V, Izpisúa Belmonte JC. Control of vertebrate limb outgrowth by the proximal factor Meis2 and distal antagonism of BMPs by Gremlin. Mol Cell. 1999;4:839-49.

30. Mercader N, Leonardo E, Azpiazu N, Serrano A, Morata G, Martínez-A C, Torres M. Conserved regulation of proximodistal limb axis development by Meis1/Hth. Nature. 1999;402:425-9.

31. Mercader N, Leonardo E, Piedra ME, Martínez-A C, Ros MA, Torres M. Opposing RA and FGF signals control proximodistal vertebrate limb development through regulation of Meis genes. Development. 2000;127:3961-70.

32. Yashiro K, Zhao X, Uehara M, Yamashita K, Nishijima M, Nishino J, Saijoh Y, Sakai Y, Hamada H. Regulation of retinoic acid distribution is required for proximodistal patterning and outgrowth of the developing mouse limb. Dev Cell. 2004;6:411-22.

33. Boulet AM, Capecchi MR. Multiple roles of Hoxa11 and Hoxd11 in the formation of the mammalian forelimb zeugopod. Development. 2004;131:299-309.

34. Freitas R, Zhang G, Cohn MJ. Biphasic Hoxd gene expression in shark paired fins reveals an ancient origin of the distal limb domain. PLOS ONE. 2007;2:e754.

35. Sakamoto K, Onimaru K, Munakata K, Suda N, Tamura M, Ochi H, Tanaka M. Heterochronic shift in Hox-mediated activation of Sonic hedgehog leads to morphological changes during fin development. PLOS ONE. 2009:4:e5121.

36. Tulenko FJ, Augustus GJ, Massey JL, Sims SE, Mazan S, Davis MC. HoxD expression in the fin-fold compartment of basal gnathostomes and implications for paired appendage evolution. Sci Rep. 2016;6:22720.

37. Tulenko FJ, Massey JL, Holmquist E, Kigundu G, Thomas S, Smith SME, Mazan S, Davis MC. Fin-fold development in paddlefish and catshark and implications for the evolution of the autopod. Proc Biol Sci. 2017:284:20162780.

38. Barry SN, Crow KD. The role of HoxA11 and HoxA13 in the evolution of novel fin morphologies in a representative batoid (Leucoraja erinacea). EvoDevo. 2017;8:24

39. Takezaki N, Nishihara H. Resolving the phylogenetic position of coelacanth: the closest relative is not always the most appropriate outgroup. Genome Biol Evol. 2016;8:1208-21.

40. Pascual-Anaya J, D'Aniello S, Kuratani S, Garcia-Fernandez J. Evolution of Hox gene clusters in deuterostomes. BMC Dev Biol. 2013;13(26):38.

41. Sordino P, van der Hoeven F, Duboule D. Hox gene expression in teleost fins and the origin of vertebrate digits. Nature. 1995;375:678-81.

42. Waskiewicz AJ, Rikhof HA, Hernandez RE, Moens CB. Zebrafish Meis functions to stabilize $\mathrm{Pbx}$ proteins and regulate hindbrain patterning. Development. 2001:128:4139-251.

43. Metscher BD, Takahashi K, Crow K, Amemiya C, Nonaka D, Wagner GP. Expression of Hoxa-11 and Hoxa-13 in the pectoral fin of a basal rayfinned fish, Polyodon spathula: implications for the origin of tetrapod limbs. Evol Dev. 2005;7:186-95.

44. Davis MC, Dahn RD, Shubin NH. An autopodial-like pattern of Hox expression in the fins of a basal actinopterygian fish. Nature. 2007;447:473-6.

45. Ahn D, Ho RK. Tri-phasic expression of posterior Hox genes during development of pectoral fins in zebrafish: implications for the evolution of vertebrate paired appendages. Dev Biol. 2008;322:220-33.

46. Crow KD, Amemiya CT, Roth J, Wagner GP. Hypermutability of Hoxa13A and functional divergence from its paralog are associated with the origin of a novel developmental feature in zebrafish and related taxa (Cypriniformes). Evolution. 2009;63:1574-92.

47. Crow KD, Smith CD, Cheng JF, Wagner GP, Amemiya CT. An independent genome duplication inferred from Hox paralogs in the american paddlefish-A representative basal ray-finned fish and important comparative reference. Genome Biol Evol. 2012;4:937-53.

48. Zhu M, Yu X. Stem sarcopterygians have primitive polybasal fin articulation. Biol Lett. 2009;5:372-5.
49. Gregory WK. The limbs of Eryops and the origin of limbs from fins. Science. 1911;33:848-9.

50. Gregory WK, Raven HC. Studies on the origin and early evolution of paired fins and limbs. Ann NY Acad Sci. 1941;42:273-360.

51. Rosen DE, Forey PL, Gardiner BG, Patterson C. Lungfishes tetrapods, paleontology and plesiomorphy. Bull Am Mus Nat Hist. 1981;167:159-276.

52. Shubin $\mathrm{NH}$, Alberch P. A morphogenetic approach to the origin and basic organization of the tetrapod limb. Evol Biol. 1986;20:319-87.

53. Joss J, Longhurst T. Lungfish paired fins. In: Ahlberg PE, editor. Major events in early vertebrate evolution. London: Taylor \& Francis; 2001. p. 370-6.

54. Shan Y, Gras R. 43 genes support the lungfish-coelacanth grouping related to the closest living relative of tetrapods with the Bayesian method under the coalescence model. BMC Res Notes. 2011:4:49.

55. Liang $D$, Shen $X X$, Zhang P. One thousand two hundred ninety nuclear genes from a genome-wide survey support lungfishes as the sister group of tetrapods. Mol Biol Evol. 2013;30:1803-7.

56. Johanson Z, Joss J, Boisvert CA, Ericsson R, Sutija M, Ahlberg PE. Fish fingers: digit homologues in sarcopterygian fish fins. J Exp Zool B Mol Dev Evol. 2007:308:757-68.

57. Hodgkinson VS, Ericsson R, Johanson Z, Joss JMP. The apical ectodermal ridge in the pectoral fin of the Australian lungfish (Neoceratodus forsteri): keeping the fin to limb transition in the fold. Acta Zool. 2009;90:253-63.

58. Smith MM, Okabe M, Joss J. Spatial and temporal pattern for the dentition in the Australian lungfish revealed with sonic hedgehog expression profile. Proc Biol Sci. 2009;276:623-31.

59. Cole N, Hall TE, Don EK, Berger S, Boisvert CA, Neyt C, Ericsson R, Joss J, Gurevich DB, Currie PD. Development and evolution of the muscles of the pelvic fin. PLoS Biol. 2011;9:e1001168.

60. Longhurst TJ, Joss JM. Homeobox genes in the Australian lungfish, Neoceratodus forsteri. J Exp Zool. 1999:285:140-5.

61. Edgar RC. MUSCLE: multiple sequence alignment with high accuracy and high throughput. Nucleic Acids Res. 2004;32:1792-7.

62. Hall TA. BioEdit: a user-friendly biological sequence alignment editor and analysis program for Windows 95/98/NT. Nucleic Acids Symp Ser. 1999:41:95-8.

63. Thomas-Chollier M, Leyns L, Ledent V. HoxPred: automated classification of the Hox proteins using combinations of generalised profiles. BMC Bioinform. 2007;8:247.

64. Darriba D, Taboada GL, Doallo R, Posada D. ProtTest 3: fast selection of best-fit models of protein evolution. Bioinformatics. 2011;27:1164-5.

65. Tamura K, Peterson D, Peterson N, Stecher G, Nei M, Kumar S. MEGA5: molecular evolutionary genetics analysis using maximum likelihood, evolutionary distance, and maximum parsimony methods. Mol Biol Evol. 2011;28:2731-9.

66. Guindon S, Gascuel O. A simple, fast and accurate algorithm to estimate large phylogenies by maximum likelihood. Syst Biol. 2003;52:696-704.

67. Nelson CE, Morgan BA, Burke AC, Laufer E, DiMambro E, Murtaugh LC, et al. Analysis of Hox gene expression in the chick limb bud. Development. 1996;122:1449-66.

68. Crotwell PL, Mabee PM. Gene expression patterns underlying proximaldistal skeletal segmentation in late-stage zebrafish, Danio rerio. Dev Dyn. 2007:236:3111-28.

69. Zeller R. The temporal dynamics of vertebrate limb development, teratogenesis and evolution. Curr Opin Genet Dev. 2010;20:384-90.

70. Abu-Shaar M, Mann RS. Generation of multiple antagonistic domains along the proximodistal axis during Drosophila leg development. Development. 1998;125:3821-30.

71. Wu J, Cohen SM. Proximodistal axis formation in the Drosophila leg: subdivision into proximal and distal domains by Homothorax and Distal-less. Development. 1999;126:109-17.

72. Pechmann M, Khadjeh S, Sprenger F, Prpic NM. Patterning mechanisms and morphological diversity of spider appendages and their importance for spider evolution. Arthropod Struct Dev. 2010:39:453-67.

73. Boisvert CA. The pelvic fin and girdle of Panderichthys and the origin of tetrapod locomotion. Nature. 2005:438:1145-7.

74. Tamura K, Yonei-Tamura S, Belmonte JCl. Differential expression of Tbx4 and Tbx5 in zebrafish fin buds. Mech Dev. 1999;87:181-4.

75. Cooper KL, Hu JK, ten Berge D, Fernandez-Teran M, Ros MA, Tabin CJ. Initiation of proximal-distal patterning in the vertebrate limb by signals and growth. Science. 2011;332:1083-6. 
76. Cooper K, Sears KE, Uygur A, Maier J, Stephan-Backowski K, Brosnahan M, et al. Patterning and post-patterning modes of evolutionary digit loss in mammals. Nature. 2014;511:41-5.

77. Roselló-Díez A, Ros MA, Torres M. Diffusible signals, not autonomous mechanisms, determine the main proximodistal limb subdivision. Science. 2011;332:1086-8.

78. Woltering JM, Duboule D. The origin of digits: expression patterns versus regulatory mechanism. Dev Cell. 2010;18:526-32.

79. Tarchini B, Dubuole D, Kmita M. Regulatory constraints in the evolution of the tetrapod limb anterior-posterior polarity. Nature. 2006;443:985-8.

80. Andrey G, Montavon T, Mascrez B, Gonzalez F, Noordermeer D, Leleu M, et al. A switch between topological domains underlies HoxD genes collinearity in mouse limbs. Science. 2013;340:1234167.

81. Johanson Z. Evolution of paired fins and the lateral somitic frontier. J Exp Zool B Mol Dev Evol. 2010;314:347-52.

82. Cohn MJ, Lovejoy CO, Wolpert L, Coates MI. Branching, segmentation and the metapterygial axis: pattern versus process in the vertebrate limb. BioEssays. 2002;24:460-5.
83. Cloutier R, Ahlberg PE. Morphology, characters, and the interrelationships of basal sarcopterygians. In: Stiassny MLJ, Parenti LR, Johson GD, editors. Interrelationships of fishes. San Diego: Academic; 1996. p. 445-79.

84. Ahlberg PE, Johanson Z. Osteolepiforms and ancestry of tetrapods. Nature. 1998;395:792-4.

85. Sheeba CJ, Andrade RP, Palmeirim I. Mechanisms of vertebrate embryo segmentation: common themes in trunk and limb development. Semin Cell Dev Biol. 2016;49:125-34.
Ready to submit your research? Choose BMC and benefit from:

- fast, convenient online submission

- thorough peer review by experienced researchers in your field

- rapid publication on acceptance

- support for research data, including large and complex data types

- gold Open Access which fosters wider collaboration and increased citations

- maximum visibility for your research: over $100 \mathrm{M}$ website views per year

At BMC, research is always in progress.

Learn more biomedcentral.com/submissions 